\title{
DISTRIBUTION OF BOTRYOSPHAERIA SPECIES CAUSING GRAPEVINE DIEBACK AND DECLINE IN NEW ZEALAND VINEYARDS
}

\author{
J. BASKARATHEVAN, M.V. JASPERS, E.E. JONES \\ and H.J. RIDGWAY \\ Bio-Protection and Ecology Division, Lincoln University, Lincoln 7647, \\ New Zealand \\ Corresponding author: baskaraj@lincoln.ac.nz
}

Worldwide, 11 species of Botryosphaeria have been isolated from grapevines in association with a wide range of decline and dieback symptoms. Currently there is little knowledge on what species are present in New Zealand. A comprehensive survey was carried out, during June to December 2007, to collect Botryosphaeria species from New Zealand vineyards. More than 450 isolates, including B. parva, B. lutea, B. australis, $B$. stevensii, $B$. obtusa and $B$. iberica, were isolated from symptomatic material. No correlation was observed between the species of Botryosphaeria and grapevine variety or age. The highest incidence of Botryosphaeria species $(97.7 \%)$ was from Blenheim and lowest $(16.4 \%)$ was from Otago. The most commonly isolated species was $B$. parva followed by $B$. stevensii. Fusicoccum type Botryosphaeria species, such as $B$. parva and B. lutea, were more prevalent in the North Island and Diplodia type species, including $B$. stevensii and B. obtusa, dominated in the South Island. It is likely that the Botryosphaeria species distribution in New Zealand is influenced by climatic conditions. This information has implications for development of control strategies.

\section{PHYTOTOXICITY OF PHOSPHORUS ACID IN LEUCODENDRON 'SAFARI GOLDSTRIKE'}

\author{
S.G. CASONATO, M.A. MANNING, P.A. RHEINLÄNDER \\ and R.A. FULLERTON
}

\section{HortResearch, Private Bag 92 169, Mt Albert, Auckland 1041, New Zealand \\ Corresponding author: scasonato@hortresearch.co.nz}

The efficacy of phosphorous acid (Foli-R-Fos ${ }^{\circledR}$ ) was tested for the control of Phytophthora cinnamomi in the cut flower Leucodendron 'Safari Goldstrike'. The fungicide was applied monthly in accordance with the prescribed label rate commencing in December 2005. During the winter months of 2006, phytotoxicity was observed in the treated plants. The treatment was suspended for 2 months to avoid further damage, after which time the foliar applications began again. No plant deaths caused by P. cinnamomi occurred in the treatments with the phosphorous acid, whereas there was a $20 \%$ death rate in the untreated plots. Growers should be aware of potential phytotoxicity from phosphorus acid on Leucodendron 'Safari Goldstrike' as it can cause stunting of the plants and affect the quality of the blooms. Application on Leucodendron 'Safari Goldstrike' should be made with caution during winter months when plants are not actively growing. Further work should be undertaken to determine whether using lower rates of the chemical during the winter months, when the plants are apparently more susceptible to infection, would result in less phytotoxicity. 